Irina Natsumi Hiraoka Moriyama ${ }^{a}$

Valéria Ramos Soares Pinto ${ }^{b}$

Liliane Graça Santana a

Alexandre Custódio Pinto ${ }^{b}$

Roberta Melo Vello Poldi ${ }^{c}$

Isabel Muniz de Almeida ${ }^{c}$

\section{Prevenção da exposição ocupacional ao benzeno em trabalhadores de postos de revenda de combustíveis: a experiência do estado do Espírito Santo}

\author{
Preventing gas stations workers' occupational exposure to \\ benzene: the experience of Espírito Santo state, Brazil
}

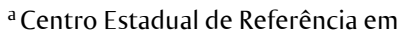
Saúde do Trabalhador do Espírito Santo. Cariacica, ES, Brasil.

${ }^{\text {b }}$ Fundação Jorge Duprat Figueiredo de Segurança e Medicina do Trabalho. Centro Estadual do Espírito Santo. Vitória, ES, Brasil.

' Secretaria Municipal de Saúde de Vitória. Coordenação de Vigilância e Saúde do Trabalhador. Vitória,ES, Brasil.

Contato:

Irina Natsumi Hiraoka Moriyama

E-mail:

irina.cerest@gmail.com

Os autores declaram que o trabalho não foi subvencionado e que não há conflitos de interesses.

O trabalho não foi baseado em tese/ dissertação e não foi apresentado em reunião científica.

\section{Resumo}

Objetivo: descrever e analisar ações desenvolvidas pela Comissão Estadual do Benzeno do Espírito Santo (CEBz/ES) voltadas à prevenção da exposição ocupacional ao benzeno em postos de revenda de combustíveis (PRC), em Vitória/ES. Métodos: foram analisadas as ações desenvolvidas a partir das parcerias estabelecidas pela CEBz/ES, entre os anos de 2012 a 2015, de modo a subsidiar sua continuidade nas frentes de: a) Diagnóstico situacional dos PRC; b) Educação em Saúde; e c) Vigilância nos ambientes de trabalho com articulação entre diferentes órgãos do governo e sindicatos. Resultados: destacam-se a ampliação do conhecimento, pelos membros da CEBz/ES, sobre os processos de trabalho e condições de funcionamento dos PRC; o fortalecimento e ampliação das parcerias interinstitucionais na realização das ações de vigilância em saúde; e a implementação de ações de educação em saúde destinadas aos empregadores, trabalhadores, sindicatos e profissionais da área de saúde do trabalhador. Conclusão: o alcance destes resultados indica a potencialidade deste processo de construção e articulação interinstitucional, além de possibilitar a aplicação dessa experiência em outros municípios.

Palavras-chave: saúde do trabalhador; exposição ocupacional; benzeno.

\begin{abstract}
Objective: to describe and analyze actions developed by the State Commission of Benzene of Espírito Santo (CEBz/ES) aimed at the prevention of occupational exposure to benzene on gas stations (GS), in Vitória, capital of Espírito Santo state, Brazil. Methods: we analyzed actions developed through partnerships established by the CEBz/ES from 2012 to 2015 regarding: a) The situational diagnosis of GS; b) Health Education activities; and c) Surveillance of working environments through articulation between different government agencies and trade unions. Results: this analysis highlights the CEBz/ES members' enlargement of knowledge about the work processes and the operation conditions of the GS located in Vitoria/ES; the strengthening and expansion of inter-institutional partnerships when carrying out health surveillance activities; and the implementation of health education activities aimed at employers, employees, trade unions and occupational health professionals. Conclusion: the achievement of these results indicates the potentiality of this inter-institutional process of articulation and actions construction, in addition to enabling the application of that experience in other cities.
\end{abstract}

Keywords: occupational health; occupational exposure; benzene. 


\section{Introdução}

Este relato apresenta o desenvolvimento de ações voltadas à prevenção da exposição ocupacional ao benzeno em trabalhadores de postos de revenda de combustíveis (PRC), realizadas no município de Vitória, capital do estado do Espírito Santo (ES), no período compreendido entre os anos de 2012 a 2015.

O benzeno é extraído do petróleo ou do carvão mineral, sendo considerado uma importante matéria-prima na indústria petroquímica. Conhecido como de segunda geração, é a quinta substância mais produzida em volume no mundo ${ }^{1}$. É um contaminante universal, altamente tóxico para a saúde humana e ambiental e apresenta toxicidade mesmo em doses inferiores a 1,0 ppm. Não há, portanto, limite seguro de exposição a essa substância, considerada a quinta de maior risco químico pelo Programa das Nações Unidas de Segurança Química ${ }^{2-5}$.

A exposição ao benzeno ocorre principalmente através do ar, pela via respiratória e também pelas vias cutânea e digestiva, sendo esta geralmente acidental $^{3}$. Segundo estudos de exposição ocupacional realizados na União Europeia, as principais fontes de exposição são as indústrias químicas, de petróleo, de plástico, de madeira, de metalurgia e siderurgia, o comércio atacadista e varejista, e o transporte terrestre. É importante destacar que os trabalhadores estão expostos não somente na indústria, mas em toda a cadeia produtiva e da logística em que esse produto se faz presente ${ }^{6}$. Essa exposição pode causar intoxicações agudas e crônicas ${ }^{3}$, e o conjunto de seus efeitos é denominado benzenismo.

Ao ser absorvido pelo organismo, o benzeno produz efeitos nocivos aos sistemas imunológico, endócrino e nervoso central e, principalmente, no processo de formação sanguínea, sendo reconhecido como elemento cancerígeno e hematotóxico, responsável por patologias como leucemias e linfomas ${ }^{3,4}$. Os efeitos no sistema nervoso central da intoxicação aguda por benzeno são: narcose, excitação seguida de sonolência, tonturas, cefaleias, náuseas, taquicardia, dificuldade respiratória, tremores, convulsões e perda da consciência, podendo levar à morte por arritmia cardíaca ${ }^{3,4}$. Em decorrência de seus efeitos prejudiciais à saúde, o benzeno é alvo de ações de controle de exposição e vigilância em saúde a nível mundial ${ }^{1,5}$.

No panorama internacional, o benzeno teve seus primeiros registros de uso industrial em 1850, sendo de 1862 o primeiro relato de intoxicação aguda resultante em morte de um trabalhador na Inglaterra. A partir do início do século XX, com a descoberta de diversos outros usos da substância, o benzeno teve sua utilização exponencialmente crescente, bem como estabelecidos seus prejuízos relacionados à intoxicação crônica para a saúde humana. Em 1922, houve uma tentativa bem-sucedida de sua substituição nas indústrias inglesas, porém, as descobertas de seus potenciais usos não paravam de surgir, aumentando a população de trabalhadores exposta ${ }^{7}$.

No Brasil, país de industrialização tardia, essa questão ganha corpo quase um século depois, em 1932, com uma legislação que proíbe o trabalho de mulheres em atividades com exposição ao benzeno. E também, mais tarde, tendo como pano de fundo a política desenvolvimentista do governo de Juscelino Kubitschek, com a aceleração do processo de industrialização do país e o início da produção de benzeno em território nacional, porém sem o acúmulo material histórico de países com episódios importantes de enfrentamento à exposição ocupacional ao benzeno, como Inglaterra, Itália e Estados Unidos.

Com o crescimento econômico do país, houve a construção de grandes polos petroquímicos e siderúrgicos nas cidades de Cubatão (SP), Camaçari (BA), Volta Redonda (RJ) e Serra (ES), nos anos 1980. É nesse período, paralelamente ao fim da Ditadura Militar ${ }^{7}$, que ocorre uma epidemia de doenças causadas pela exposição ocupacional ao benzeno que atinge principalmente trabalhadores metalúrgicos e siderúrgicos nos municípios paulistas de Cubatão e Santos. Denunciada pelo movimento sindical da Baixada Santista, a chamada epidemia de benzenismo desencadeou uma ampla discussão envolvendo trabalhadores, órgãos de governo e o patronato.

Após mais de dez anos, o movimento teve como resultado a assinatura do Acordo do Benzeno, em $1995^{8}$, que estabeleceu, entre outras cláusulas, a criação da Comissão Nacional Permanente do Benzeno (CNPBz), reconhecendo instâncias locais e regionais de negociação. Assim como em outros estados e municípios, o Espírito Santo constituiu sua representação local no início dos anos 2000: a Comissão Estadual do Benzeno no Espírito Santo (CEBz/ES). Atualmente sua composição se dá por representantes das esferas de Governo Federal e estadual: Superintendência Regional do Trabalho do Espírito Santo (SRTE/ES), Centro Estadual do Espírito Santo da Fundação Jorge Duprat Figueiredo de Segurança e Medicina do Trabalho (Fundacentro/ CEES), Centro Estadual de Referência em Saúde do Trabalhador (Cerest/ES), Coordenação de Vigilância em Saúde do Trabalhador da Secretaria Municipal de Saúde de Vitória (Semus/CVST/ES); representantes dos trabalhadores: Sindicato dos Metalúrgicos no Estado do Espírito Santo (Sindimetal/ES), Sindicato dos Petroleiros do Espírito Santo (Sindipetro/ ES), Grupo de Representação de Trabalhadores do Benzeno da Petrobras (GTB/Petrobras), Sindicato dos Trabalhadores de Postos de Revenda de Combustíveis 
(Sinpospetro/ES); e representantes dos empregadores: ArcelorMittal Tubarão, Instituto Brasileiro de Petróleo da Petrobras (IBP/Petrobras/ES) e Sindicato do Comércio Varejista de Derivados de Petróleo do Estado do Espírito Santo (Sindipostos/ES), este último com inserção recente, em maio de 2015.

O Acordo do Benzeno, embora tenha reconhecido o risco de exposição ao benzeno nas atividades de armazenamento e distribuição de combustíveis, restringiu-se a indicar que essas atividades devessem ser abordadas posteriormente, em regulamentação própria. Assim, há vinte anos, ficou registrada a necessidade de se discutir e tratar do assunto.

Após dezesseis anos, em 2011, foi constituída a Subcomissão de Postos Revendedores de Combustíveis, pela Portaria $\mathrm{n}^{\circ} 252$, de 04 de agosto de $2011^{9}$, com o objetivo de avaliar a exposição dos trabalhadores desse segmento ao benzeno. Essa Subcomissão, de composição tripartite, ficou sob coordenação de representante da Secretaria de Inspeção do Trabalho. Em alguns estados, anteriormente a essa portaria, foram iniciadas ações através de projetos ou de suas respectivas comissões estaduais ou regionais do benzeno, constituindo-se uma base para a elaboração de propostas para a prevenção nesse setor.

Em consonância com o movimento nacional e considerando a inserção produtiva do Espírito Santo na economia do país como polo petroquímico ${ }^{8}$, em 2002, o Centro Estadual de Referência em Saúde do Trabalhador elaborou o projeto Benzeno, cujo objetivo era, dentre outros, propor medidas para minimizar a exposição dos trabalhadores e da população em geral.

O projeto teve início com a análise de exames laboratoriais de frentistas do município de Vitória, não tendo sido constatada nenhuma alteração dos níveis de referência das coletas desses trabalhadores. Dessa forma, a ação perdeu sua potência institucional, tendo esta frente sido retomada apenas em 2012, devido à participação do Cerest/ES na CEBz/ES, onde os trabalhadores dos PRC encontram-se representados pelo seu sindicato.

Assim, este trabalho, elaborado pelos trabalhadores membros da Rede de Formação e Pesquisa em Saúde do Trabalhador (Refopesat), tem como objetivo descrever e analisar as ações voltadas à prevenção da exposição ocupacional ao benzeno em trabalhadores de PRC, desenvolvidas a partir das parcerias estabelecidas pela $\mathrm{CEBz} / \mathrm{ES}$.

A Refopesat é a institucionalização de parcerias e articulações entre profissionais e instâncias relacionadas à Saúde do Trabalhador no estado do Espírito Santo que, implicados com a efetivação de ações nesse campo sob a ótica da Política Nacional de Saúde do Trabalhador e da Trabalhadora (PNSTT), é, também, uma tentativa de resistência e fortalecimento frente às vulnerabilidades destas parcerias quando dependentes da perspectiva da gestão/governo de tais instituições. Constituem a Refopesat: Cerest/ES, Fundacentro/ CEES, Universidade Federal do Espírito Santo (UFES) e as Vigilâncias em Saúde do Trabalhador dos Municípios de Vitória e de Anchieta.

\section{Percurso metodológico}

Trata-se de um relato de experiência que tem como base as ações voltadas à prevenção da exposição ocupacional ao benzeno em trabalhadores de PRC realizadas no município de Vitória/ES, entre os anos de 2012 e 2015.

\section{Planejando as ações...}

Em 2012, foi instituído um subgrupo de trabalho da CEBz/ES para avaliar a atividade laboral dos frentistas de PRC e apresentar propostas e estratégias para redução e prevenção da exposição ao benzeno. Dentre elas, destacam-se as principais frentes: a) Diagnóstico situacional dos PRC do município de Vitória; b) Educação em Saúde, com elaboração e realização de atividades educativas acerca da exposição ocupacional ao benzeno para empregadores e empregados de PCR, além da produção de material informativo e campanha aberta à população; e c) Vigilância nos ambientes de trabalho.

Para a operacionalização de ações que visaram a concretização dessas propostas, as instituições membros da CEBz/ES compartilharam responsabilidades, organização e realização das ações, de acordo com suas competências de atuação.

\section{... e analisando seus resultados}

No âmbito da CEBz/ES, as ações foram avaliadas em suas reuniões ordinárias, com registro em ata e, especificamente nos cursos, foi adotado um questionário semiestruturado como meio de proporcionar o registro das impressões e/ou reflexões dos participantes acerca da ação e sua temática. Para tanto, foi realizada análise documental de atas, relatórios e apresentações produzidos pela CEBz/ES e seus membros, e de avaliações e listas de presença dos cursos. Além disso, os relatos de atores que estiveram envolvidos nas ações, como os componentes da Refopesat, o coordenador da CEBz/ES, o presidente do Sinpospetro/ES, entre outros, também compõem o escopo de dados analisados para a apresentação e análise das ações descritas a seguir. 


\section{Realizando as ações}

A partir da produção do subgrupo de trabalho da CEBz/ES para avaliar atividade laboral dos frentistas de PRC, as ações desenvolvidas serão aqui apresentadas nas três frentes: Diagnóstico situacional; Educação em Saúde; Vigilância nos ambientes de trabalho.

\section{Diagnóstico situacional dos PRC do município de Vi- tória}

Dando início à efetivação das propostas, a primeira etapa foi realizar um diagnóstico situacional a fim de subsidiar o conhecimento dos membros da CEBz/ES sobre esses ambientes de trabalho, bem como identificar as nuances do trabalho real ali exercido, visando uma atuação fundamentada dos atores no desenvolvimento das ações. Entendendo o trabalho real como as transgressões que os trabalhadores cometem frente às prescrições (tarefas) que lhes são dadas, a fim de operacionalizá-las ${ }^{10}$.

Para tanto, foram organizadas visitas em uma amostra aleatória de oito postos de revenda de combustíveis da Região Metropolitana de Vitória, realizadas por profissionais do Cerest Estadual e Superintendência Regional do Trabalho. Nas visitas, foram identificados e registrados diversos aspectos sobre as condições de segurança e higiene desses ambientes de trabalho.

\section{Educação em Saúde}

Esta frente envolveu dois momentos de exposição dialogada e a produção de material educativo impresso.

Após análise dos resultados das visitas realizadas nos postos, a CEBz/ES sistematizou e organizou uma devolutiva aos donos de PRC acerca das condições dos ambientes de trabalho, sendo também realizada uma apresentação sobre efeitos nocivos à saúde provocados pelo benzeno. Dos 36 representantes de postos convocados, 29 compareceram, totalizando $80 \%$ da população convocada.

O segundo momento educativo foi voltado aos próprios frentistas. Essa etapa foi precedida por uma negociação junto aos donos de postos, para a liberação de dois trabalhadores de cada PRC para participação no evento que abordou, principalmente, os riscos e as medidas de prevenção à exposição ao benzeno. Foram organizados dois dias de curso, de forma a possibilitar o comparecimento de um frentista de cada posto em um dos dias de realização do evento. Dos 72 frentistas previstos para participarem da capacitação, 53 compareceram, tendo sido abrangidos, portanto, 74\% do número total de liberação de participantes pactuado com os donos de PRC.

Ambos os cursos, tanto para os donos de postos como para os frentistas, tinham um conteúdo comum: a apresentação dos efeitos nocivos à saúde da exposição ao benzeno. Foram abordados os seguintes tópicos: o que é o benzeno, formas de absorção, efeitos agudos e crônicos na saúde, noções de toxicologia e formas de prevenção, tratamento e encaminhamento dos casos de intoxicação pela substância.

Para os donos de postos, com base nas visitas realizadas anteriormente e nas inadequações encontradas, foram abordadas as principais inconformidades legais para as quais os proprietários de PRC devem buscar adequação, como a implementação de Normas Regulamentadoras referentes ao Programa de Prevenção de Riscos Ambientais (PPRA), Programa de Controle Médico de Saúde Ocupacional (PCMSO), Equipamento de Proteção Individual (EPI), Cuidado e Aterramento de Compressores, Condições Sanitárias e de Conforto, implantação de Comissão Interna de Prevenção de Acidentes (CIPA) ou indicação do designado (um empregado que, como prevê a Norma Regulamentadora 5, desempenhe as atividades dessa comissão) e seu respectivo curso.

Além desses encontros, foi produzido material educativo direcionado principalmente aos trabalhadores desse setor, mas que atingisse também a população em geral. Foi elaborado um folder sobre os efeitos nocivos do benzeno, em especial, à saúde humana; e encontra-se em processo de elaboração outro, sobre a importância do limite de abastecimento até o automático, voltado principalmente à população consumidora. A CEBz/ES optou pela elaboração desse dispositivo, uma vez que permite a transmissão da informação de forma objetiva, apresenta baixo custo e maior facilidade em sua reprodução gráfica.

Para elaboração desse material, foi constituído um grupo de trabalho que pesquisou outros materiais semelhantes produzidos em outros estados, adequando-o à realidade e ao momento do estado do Espírito Santo. Esse material teve distribuição nos eventos descritos anteriormente e em ações que o sindicato dos trabalhadores promove nos PRC, acompanhando e informando os frentistas in loco.

As atividades de educação em saúde, em especial os momentos de formação e encontro com os donos de postos e com os frentistas, foram muito ricos do ponto de vista da troca de informação e oportunidade de ouvir seus participantes. A CEBz/ES pôde apreender que ambos os grupos, de um modo geral, desconheciam os riscos e, quando detinham algum tipo de informação, demonstraram desconhecimento mais técnico e aprofundado dos efeitos prejudiciais 
que o benzeno pode causar à saúde, suas rotas de propagação e vias de contaminação no organismo.

A demonstração de preocupação e da falta de conhecimento sobre os riscos ocupacionais referentes à exposição ao benzeno apresentou-se de maneira significativa, assim como a necessidade de sua prevenção. Assim, em ambos os momentos, essas ações foram avaliadas como positivas, tanto pelos participantes quanto pela Comissão.

Cabe enfatizar que a CEBz/ES conta, desde dezembro de 2011, com representação dos trabalhadores dos postos de revenda de combustíveis. Essa comissão, na visão da diretoria do Sinpospetro/ES, é uma instância que cumpre sua missão de oferecer subsídios técnicos a seus participantes, propiciando uma discussão e apropriação qualificada sobre o tema, além de embasamento nas reivindicações em defesa da saúde quanto à exposição ao benzeno por parte, principalmente, dos trabalhadores.

É importante ressaltar que, nos três anos de sua constituição, o Sinpospetro/ES realizou duas importantes conquistas em relação à prevenção da exposição ao benzeno por meio de negociação direta com os empregadores, materializadas pela inclusão de cláusulas nos acordos coletivos que estabelecem a proibição do uso da "flanelinha", em 2014, e abastecimento até o automático, conquista concluída no acordo fechado em 2015 ${ }^{11}$. Ambas visam reduzir a exposição dos trabalhadores ao benzeno:

\section{CLÁUSULA QUINQUAGÉSIMA QUARTA - USO DE} FLANELINHA

Fica estabelecido que os empregados não utilizarão flanelinhas durante suas atividades, evitando contato e contaminação através de combustíveis.

CLÁUSULA QUINQUAGÉSIMA QUINTA - ABASTECIMENTOS ATÉ O AUTOMÁTICO

Fica proibido que os postos de combustíveis permitam preencher o tanque de combustível dos veículos após o travamento automático de segurança da bomba de segurança de abastecimento (desarme automático).

A comunicação para os empregados e clientes se dará através de adesivos fixados próximos às bombas abastecedoras, no tamanho 30x20, sobre o abastecimento até o automático.

Essa experiência do movimento sindical dos trabalhadores de PRC no estado destaca-se, uma vez que, de acordo com o que a CEBz/ES acompanha por meio das demais comissões do benzeno, tem sido objeto de negociação em outros estados, em suas esferas governamentais e, portanto, além de acompanhar o cenário nacional (proibição do abastecimento após o travamento do automático), o Sinpospetro/ES foi o único sindicato no país que optou pela pactuação via Convenção Coletiva. As demais experiências brasileiras resultaram em legislações de âmbito local.

Um instrumento de negociação coletiva, embora exija a renegociação de cada cláusula ao fim de sua vigência, neste caso de dois anos - o que não acontece com as legislações -, como envolve ambas as partes interessadas diretamente, tende a ter maior cumprimento do que as legislações ${ }^{12}$. E é nesse aspecto que o movimento dos trabalhadores aposta no que diz respeito ao cumprimento de tais direitos pactuados.

\section{Vigilância nos ambientes de trabalho}

As ações de vigilância tiveram início a partir do curso de Vigilância de Ambientes e Processos de Trabalho em PRC, com apresentação do conteúdo com técnicos de referência nacional, cujo público-alvo foram os integrantes da CEBz/ES, representantes de entidades dos trabalhadores de PRC e profissionais que atuam nos diversos órgãos que realizam ações em Saúde do Trabalhador, incluindo aqueles que compõem a Rede Nacional de Atenção Integral à Saúde do Trabalhador (Renast).

O curso teve como objetivo a formação de equipes técnicas e interinstitucionais que atuariam em conjunto nas ações de vigilância. Abordou, em sua programação, os aspectos gerais da exposição ao benzeno; diagnóstico preliminar das condições dos ambientes de trabalho dos PRC; identificação e avaliação de risco nos PRC; análise do processo de trabalho; instrumentos e métodos (ficha, relatório) para vigilância; principais medidas coletivas e individuais para a prevenção aos riscos nos ambientes de trabalho visando a proteção dos trabalhadores; sistema de controle ambiental e medidas para redução da exposição a voláteis orgânicos; apresentação da proposta de Anexo da NR 9, contendo requisitos mínimos de segurança e saúde no trabalho em instalações de abastecimento de combustíveis contendo benzeno; e avaliação do curso (dialogada em grupo e escrita individual).

Após o curso, membros da CEBz/ES reuniram-se com equipes da Vigilância Ambiental e Sanitária do município de Vitória e do Instituto Estadual do Meio Ambiente e Recursos Hídricos (Iema) e, a partir do Roteiro de Vigilância em PRC apresentado no curso, foram propostas modificações tendo em vista sua aplicação nos postos do estado. O documento final foi apresentado e aprovado em reunião ordinária da $\mathrm{CEBz} / \mathrm{ES}$, assim como o cronograma das visitas. Na mesma reunião, por consenso, ficou estabelecido que seria feito convite ao sindicato patronal (Sindipostos/ ES) e de trabalhadores (Sinpospetro) para apresentação da proposta de ação de vigilância a ser iniciada, seus objetivos e abrangência. 
A reunião realizada pela CEBz/ES, que contou com a participação de ambos os sindicatos, apresentou-se de forma positiva, tornando possível um amplo conhecimento das ações realizadas por essa Comissão e, assim, possibilitou um processo mais participativo por parte dos envolvidos.

\section{Em busca de horizontes para consolidação das ações}

A análise das ações realizadas pelos integrantes e parceiros da CEBz/ES permitiu identificar a potencialidade desse processo de construção, articulação e operacionalização interinstitucional, em prol da melhoria nas condições de saúde e trabalho da população trabalhadora e em geral. Seguindo as ações previstas, houve uma tendência ao fortalecimento das parcerias entre as instituições membros da CEBz/ES, propiciando, também, o envolvimento da sociedade.

Dentre as ações posteriores previstas, destaca-se a campanha aberta à população que visa subsidiar o trabalhador frentista em seu direito de abastecer até o limite automático, que se apresenta como um grande desafio, uma vez que pretende informar à população consumidora os riscos de excedê-lo.

Outra ação que ampliará o rol de parcerias nessa temática e que tornará os resultados mais integrais e integrados é a realização de vigilância em ambientes de trabalho, a partir de vários olhares: as Secretarias de Meio Ambiente (estadual e municipal), vigilância ambiental e sanitária, Cerest/ES e MTE.

Referente à Convenção Coletiva da categoria de PRC, ainda que a pactuação da Convenção 2015/2016 tenha se dado de forma fluida entre sindicatos patronal e de trabalhadores, ressalta-se a importância de ambos e do governo na composição da Comissão para o fortalecimento e a legitimação do caráter tripartite da mesma. Dessa forma, a integração do sindicato patronal, o Sindipostos, à CEBz/ ES foi um importante ganho para ampliar a discussão sobre exposição ao benzeno e discutir estratégias para melhoria das condições dos postos de trabalho.

Espera-se, ao final das ações, que a metodologia adotada pela CEBz/ES, em parceria com outras instituições, possibilite uma análise comparativa da situação atual e da situação após as modificações implementadas por meio da vigilância dos ambientes de trabalho e pactuações das mudanças para sua melhoria, que poderá ocorrer por negociação de ajustes coletivos para todos os postos do estado.

Dessa forma, um desafio apontado é a discussão de medidas de proteção coletiva que extrapolem o conteúdo estabelecido nos dispositivos legais como, por exemplo, aquisição de equipamentos de captação de vapores que emanam durante o abastecimento dos veículos e nas operações de descarregamento dos caminhões tanques nos postos. Considerando que ainda não é possível eliminar o benzeno da gasolina e que estes equipamentos de captação não são obrigatórios, ressaltamos a observância da NR 9, "b" ${ }^{13}$, que especifica sobre a adoção de medidas preventivas:

9.3.5.2. O estudo, desenvolvimento e implantação de medidas de proteção coletiva deverá obedecer à seguinte hierarquia:

a) medidas que eliminam ou reduzam a utilização ou a formação de agentes prejudiciais à saúde;

b) medidas que previnam a liberação ou disseminação desses agentes no ambiente de trabalho;[...]

A partir do caminho traçado pela CEBz/ES e seus membros, o intuito é de se expandir para todo o estado as ações de sensibilização aos frentistas e donos de postos de combustíveis, dentro de cada singularidade local, a partir da atuação e articulação dos Cerests Regionais, referências técnicas em Saúde do Trabalhador nos municípios e Superintendências Regionais do Trabalho.

E, para além do intuito de compartilhar essa experiência, o processo de escrita apresentou-se como um dispositivo para a avaliação crítica e sistematizada do desenvolvimento das ações, favorecendo uma reflexão sobre a prática e a tomada de decisões futuras pela equipe envolvida em sua continuidade ${ }^{14}$, uma vez que a Refopesat tem, em sua maioria, representantes na CEBz/ES.

É possível, portanto, ampliar este processo de escrita a demais ações realizadas no Espírito Santo no âmbito da Saúde do Trabalhador, apresentando-se como uma estratégia para a criação de memória institucional e histórica desse campo no estado, evitando perdas ao decorrer do caminho, como ocorreu com registros acerca de projetos anteriores, como no caso do projeto Benzeno, realizados pelas instituições membros da Refopesat, antes de sua composição.

Assim, compreendemos que as parcerias de âmbito suprainstitucional declaradas no presente artigo (CEBz/ES e Refopesat) apresentam-se como uma saída criativa e potente na efetivação de ações no campo da Saúde do Trabalhador ${ }^{15}$.

No que diz respeito aos principais resultados do programa, este trabalho possibilitou a ampliação do conhecimento sobre os ambientes de trabalho de PRC, a partir de diversos olhares, o que vem permitindo uma intervenção mais qualificada e eficaz sobre estes ambientes. Destaca-se, ainda, a realização 
das atividades educativas, por meio de cursos de capacitação e elaboração de material informativo, que envolveu diversas instituições responsáveis pela saúde e segurança dos trabalhadores, e que tem como perspectiva a realização de campanhas e ações envolvendo a sociedade. E, ainda que inicial a abrangência das ações ao longo desses anos, ressaltamos como principais resultados a busca pelo acompanhamento e retomada na inserção da atuação da CEBz/ ES em consonância com o cenário nacional; tanto para fortalecer a pauta dos enfrentamentos frente aos danos causados aos trabalhadores expostos ao benzeno, quanto para alinhar e atualizar as discussões locais acerca do tema.

\section{Contribuições de autoria}

Todos os autores contribuíram em todas as etapas: elaboração do projeto e delineamento, levantamento e/ ou análise e interpretação dos dados, elaboração e aprovação final da versão a ser publicada.

\section{Agradecimentos}

Agradecemos à CEBz/ES, cujos membros estiveram sempre dispostos a nos auxiliar no resgate de datas, acontecimentos e registros, e aos demais membros da Refopesat.

\section{Referências bibliográficas}

1. United Nations Environment Programme. Global Chemicals Outlook: Towards Sound Management of Chemicals. New York: Unep; 2013. [Citado em 2015 jun 2]. Disponível em: http://bit.ly/1EuQZTE.

2. Moura-Correa MJ, Jacobina AJR, Santos SA, Pinheiro RDC, Carneiro Menezes MAC, Tavares AM, et al. Exposição ao benzeno em postos de revenda de combustíveis no Brasil: Rede de Vigilância em Saúde do Trabalhador (Visat). Ciênc Saúde Coletiva. 2014;19:4637-48.

3. Ruppenthal, JE. Toxicologia. 1. ed. Santa Maria: Universidade Federal de Santa Maria/Colégio Técnico Industrial de Santa Maria; 2013.

4. Arcuri, ASA (Org.). Efeitos da exposição ao benzeno para a saúde. 1. ed. São Paulo: Fundacentro; 2012.

5. Machado JMH, Costa DF, Cardoso LM, Arcuri ASA. Alternativas e processos de vigilância em saúde do trabalhador relacionados à exposição ao benzeno no Brasil. Ciênc Saúde Coletiva. 2013; 8:913-21.

6. Ministério da Saúde. Câncer relacionado ao trabalho: leucemia mielóide aguda/síndrome mielodisplásica decorrente da exposição ao benzeno. 1. ed. Brasília: Ministério da Saúde; 2006.

7. Costa, DF. Prevenção da exposição ao benzeno no Brasil. São Paulo. Tese [Doutorado em Ciências] - Faculdade de Medicina da Universidade de São Paulo; 2009.
8. Arcuri, ASA, Cardoso, LMN, organizadores. Acordo e Legislação sobre o Benzeno - 10 anos. 1. ed. São Paulo: Fundacentro; 2005.

9. Ministério do Trabalho e Emprego (Brasil). Portaria $\mathrm{n}^{\mathrm{o}}$. 252, de 04 de agosto de 2011. Constitui a Subcomissão de Postos Revendedores de Combustíveis. Brasília: Diário Oficial da União 2011;Seção 1.

10. Dejours, C. Psicodinâmica do trabalho e teoria da sedução. Psicol Estud. 2012;17:363-71.

11. Ministério do Trabalho e Emprego (Brasil). Convenção Coletiva de Trabalho 2015/2016. Registro no MTE: ES000124/2015. Brasília: MTE; 2015.

12. Silva, ML. Negociação coletiva em saúde do trabalhador: segurança em máquinas injetoras de plástico. São Paulo Perspec. 2003; 17(2):23-31.

13. Ministério do Trabalho e Emprego (Brasil). Norma Regulamentadora 9. Brasília: Diário Oficial da União 2004;Seção 1.

14. Ayres, JR. Norma e formação: horizontes filosóficos para as práticas de avaliação no contexto da promoção da saúde. Ciênc Saúde Coletiva. 2004;9:583-92.

15. Lima, FPA. Ações coordenadas em saúde do trabalhador: uma proposta de atuação supra-institucional. Rev Bras Saúde Ocup. 2009;34(119):67-78. 